http://dx.doi.org/10.18778/8142-006-8.02

\title{
A DESCENT INTO DEPARTURE AND AN EXPLORATION OF ABSENCE - MARK Z. DANIELEWSKI'S HOUSE OF LEAVES AS A PORTRAYAL OF THE SPACE OF LITERATURE
}

\section{JĘDRZEJ TAZBIR}

Institute of English Studies, University of Lodz

The article examines the content, form, and structure of Mark Z. Danielewski's complex and enigmatic debut novel House of Leaves, in the context of Maurice Blanchot's theoretical postulation of the "space of literature" - a conceptual space encountered by the writer seeking to produce a literary work of art, marked by absence, withdrawal, which renders the writer essentially alone, alienated, and separated from the work, incapable of expression or fulfilment, and instead put in the incessant presence of death and of speech without a source or an end. The novel, the essay argues, through its depiction of the eponymous house as well as its compositional and narratological experiments, both represents such a space in a more palpable, physical form, and portrays the impact it exerts upon those who come into contact with it - the protagonists, the narrators, and finally the readers all face the space which denies them immediacy, ownership, or fundamental knowledge, which dares and condemns them to venture into its abyss, where the self is brought into the danger of dissipation, and only the echoes of erased and lost meanings still resound.

Since its release in 2000, House of Leaves by Mark Z. Danielewski has stood as an intimidating challenge to prospective critics. Containing multiple narrative layers, affixed with a baroque web of references, invoking both fictional and authentic names with no inhibition, making use of avant-garde like manipulation of text as a physical object, incorporating poetry, images, collages, while at the same time playing with incompleteness and expurgation of content, the work seems ready to undermine any attempt at composing an exhaustive critique of its subject matter. It even pre-empts such endeavours by already including fictional critical comments within its own pages, many of which appear to be written in a faintly satirical manner. On the other hand, however, the text definitely offers tantalizing opportunities for literary researchers willing to follow up on numerous threads the book puts forward. Among these threads are various quotations inserted in the text without much 
in the way of additional comment. One of the more mystifying instances of that is a quote from a translation of the work by Maurice Blanchot, "whoever sees God dies" wrongly described as a translation of a phrase from the Latin Bible (388). The strange, cryptic way in which the French philosopher's words find their way into the novel definitely suggests that analysing the relationship between House of Leaves and his writings may be a worthwhile line of critical inquiry. This essay aims to present just such a link between the novel and one of Blanchot's crucial concepts, mainly that of the "space of literature" (l'espace littéraire). It will seek to show how the unnatural interior of the house together with the layers of narrative weaved around it can actually be said to represent that space and how the often distressing if not fatal experiences of the novel's various narrators are a result of engaging with it as authors. It will also trace how the theses developed by Blanchot could inform Danielewski's creative decisions made during the composition of his magnum opus.

To indicate House of Leaves' main protagonist is to select one of the multiple strands of the book's narrative as paramount, which is hardly the proper course to take. The eponymous house of leaves is on the surface a name for the setting of the novel's central events, yet only one of the three - or four, as it could be argued - main perspectives so much as sets foot in there. What is more, that perspective in particular only comes to us in a mediated form, as the "core" text of the novel is an extremely elaborate description and commentary of a largely one-man's handheld camera documentary, which, as the text's more prominent editor hastens to inform the readers right in the book's introduction, is by all indications a pure fabrication of the writer's mind. The "hero" of the plot is hence a character intratextually declared fictional right from the outset, and his story is in turn related - in a near academic style, which however becomes in places twisted and distorted - by a man who at the starting point of the novel is already deceased. The task of actually assembling and preparing the text for readers' consumption falls in turn upon yet another character and voice in the text - one whose unorthodox approach to editing involves not only liberally providing his own interpretation or more general deliberations on certain passages, but also interspersing the text with lengthy accounts of his own personal life as it unfolded during and before his occupation with the manuscript. As a result, it is the editor - Johnny Truant's - identity that is rendered the most familiar to the reader, despite his apparent lack of any direct association with the core text. Meanwhile, the identity of the actual author - who goes by the name Zampanò - remains shrouded in mystery. This remains the case even though Johnny, far from maintaining a professional detachment from the work he edits, is set on finding out the 
reason why the author - who he soon realizes was blind - would undertake to create such a vivid and comprehensive account of an apparently fictional audiovisual work.

This matter of the work's genesis turns out to be even more pressing as Johnny' life becomes alarmingly transformed by the task of bringing Zampanò's legacy to life - the task undertaken for no discernible reason other than having witnessed the text lying in a pathetic heap inside of the dead man's virtual hermitage. Confronted with the text's various mysteries, which he believes can lend insight to the mysteries of Zampanò and his sad fate, Johnny's interest in the account takes the form of an obsession taking a toll on his physical as well as mental health. Johnny's repressed past is stirred by the narrative content, is brought to haunt him alongside the apparent manifestations of unknown entities referenced in the text. Horror emerges as a near constant feature of his existence, the very foundations of which now come for him into question.

But what is it about the text that exerts such a profound effect as to invade Johnny's own subjective reality? The documentary Zampanò's work so painstakingly portrays is a found-footage film registering the experiences of a family - led by a photographer and the movie's creator Will Navidson - which, after moving into a house somewhere in Virginia, suddenly starts observing certain physical anomalies. These start out in innocuous enough forms (such as inconsistent dimensions of a room when being measured from the inside and when from the outside), which however turn out to herald an inexplicable manifestation of an opening to a vast, immeasurable, dark dimension of endless and constantly changing hallways, stairways and abyssal open spaces, accessible and discernible only from inside of the building, to an unequivocal contempt of the scientific laws supposed to govern our reality. The account, titled The Navidson Record, found by Johnny in the form of a bundle of disjointed pages, itself represents a veritable literary maze featuring countless footnotes, appendices, and experiments with the text's composition, rendering his task infinitely demanding and timeconsuming. The text refuses to acknowledge its fictional nature, firmly positioning itself as a serious treatise on an authentic cultural phenomenon, and reinforcing this notion by referencing and incorporating quotes from all sorts of real world commentators, from film and literary critics to psychoanalysts, celebrities, and Hollywood producers, all of which are deemed fake by Johnny. All the effort put into creating a convincing hoax, effort cut short by Zampanò's abrupt death, was apparently aimed at substantiating the reality of a profoundly disturbing and inhuman dimension residing within the Navidsons' house - a space of limitless passages from within which no "outside" can be reached, passages of palpable darkness, of 
obscure, fluid proportions, of suspended physical laws; a site of indefinable dread, "a house in which one can never be fully at home, defined by its absences," to quote Melanie Waltman (7). What could this space represent? Johnny is convinced that despite all the evidence of the actual video footage being non-existent, there is some sort of truth at the heart of The Navidson Record. This truth, as the essay intends to argue, is one that Johnny's narrative also comes to express, and it concerns the nature of experience shared by writers since the formation of literary art, namely the experience of what Maurice Blanchot terms "the space of literature."

The basis of Blanchot's concept rests on the assumption that language, especially in a literary context, is not a means of representation. Rather, it is a means of negating the reality composed by things the words (on the surface, at least) symbolize. No thing and no idea can be apprehended in writing except as "a retreat, an obscuring or effacement," a withdrawal that "opens the space in which beings appear" (6); beings which do not belong to the physical world, nor to the mind of the artist, but whose sole reality is that of the text. Essentially, "[1]iterature's space is like the place where someone dies: a nowhere" (9), a void that forbids entry. For the writer, no relationship of direct presence can be attained with that space. It may offer "the strange immediacy, foreign to presence and to any present, of remoteness itself' (11), but at the same time it puts him in the position where nothing can be grasped or appropriated, where the work "calls upon his weakness, the incapacity in him to achieve anything at all; it inspires in him a kind of numbness or stupefaction." Thus, it is also a space of exclusion and degradation, an "interminably affirmative No, which keeps on revoking all achievements" (13), leaving the writer in a state of irrevocable dissatisfaction with the work, which he cannot make to signify more than its own mere being, and of which what belongs to the writer is but a "mute collection of sterile words, the most insignificant thing in the world" (22). What is more, this thing, once written, repulses him, puts him again in "that 'separation' which he first entered in order to become attuned to what he had to write" (23). The writer is compelled to start over, but his aim remains ever "interminable." He devotes himself "to a language which no one speaks, which is addressed to no one, which has no center, and which reveals nothing" (25), condemning himself in turn to both solitude and anonymity, incapable of expressing either his own $I$ or anyone else's, with the $I$ of his work becoming no one's, endemic only to the literature's void.

The above paragraph naturally could only scratch the surface of Blanchot's theory of literature's space. Yet even such a brief overview reveals multiple points of applicability to the content of Danielewski's work. An analysis of the space manifesting itself within the novel as a metaphor for 
Blanchot's space of literature should take into account the space's features rendered by the text and the impact it exerts on the characters as well as, to some extent, on the reader. One can start by recapitulating that, as an actual entity, the house exists only in textual form even within the novel, and as such, it is "not taking place in the form of any object that exists" (Mallarme, qtd. in Blanchot 42). Furthermore, not one of the narrators writes about it from the position of direct familiarity. Everything the readers learn about the house comes from a source explicitly claiming to be mediating another source; a claim that is further compounded by the apparent fictitious status of the original source, as well as by the fact that, due to the stated nature of that source (a film), it could not have been directly experienced in full by the narrator, since he is identified as blind. What follows is that the house is removed from the reader by several layers of separation, to the extent that nothing he or she reads about it can be taken at face value. It is this very space between the house and the reader that comprises the actually accessible body of the text. All information about the house comes already in the process of withdrawal and consequently does not reveal anything of substance, all that it conveys comes concealed in ambiguity, not to be seized by any firm grip of knowledge. The epistemic status of the text could hence be described as "the resurgence of the distance at which we must place anything we wish to understand or aim to grasp" (Blanchot 11).

The fact that The Navidson Record describes the house not directly, but by employing this style of mediation, may reflect Zampanò's resolution to do away with the illusion of authorial ownership of the text. By means of festooning the core text with footnotes containing remarks attributed to other people - often, but not always, fictional - he fashions an imitation of a profoundly decentralized text. Katherine Hayles claims that the use of such format indicates that the novel advocates for understanding subjectivity as a "communication circuit" and for understanding literature as "remediation" (803). Yet how can there be communication when the main voices in the text never come into contact with one another and how can there be remediation when by all accounts what is actually mediated is nothing? Instead, I would posit that Zampanò's approach is on one hand an act of obfuscation, for even the authentic persons are in the context of the text made fictional and nonexistent outside of its bounds, yet on the other it is also an admission of the text, together with the space it maintains, resides in, and recedes from, existing independently, always at a distance from any mind engaged in writing. The constant, almost obsessive footnotes and intertextual references may well be an attempt at demarcating those boundaries separating the space occupied by the text from that occupied by Zampanò - just like the measurements visibly performed in his room were an attempt at demarcating 
the material immediate space which the abyss would not be permitted to infract on. Both these attempts would then have to be deemed unsuccessful, for while the text is always outside of the writer's grasp, the writer does not enjoy the same sovereignty, but is interminably in danger of losing his selfhood to the void.

This danger, faced by virtually every significant character in the novel, definitely corresponds with what Blanchot intimated to be one of the main sources of writers' anxiety. According to his theory, a writer setting out on a pursuit of literary art is met with a feeling of "extreme repugnance at losing his grasp upon himself in the interests of that neutral force, formless and bereft of any destiny, which is behind everything that gets written" (27). While the elderly Zampanò seems reconciled with this state of things, using what is likely a pseudonym (taken from Fellini's La Strada) as a signature, and leaving behind a note expressing the hope that his writing will forever fade in time, which would mark the end of any sign of his existence (Danielewski xix), others are not ready to respond to that impression with such placid passivity (which, again citing Blanchot, is "perversely" demanded of the writer (12)). The characters featured in The Navidson Record who undertake an exploration of the house face a real test of will. One of them, an outdoorsman named Holloway, ends up going mad, fatally shooting one of his companions before taking his own life. He is, however, shown to be desperately clinging to his identity during his final moments, with the footage recording his endlessly repetitive recital of his personal details. This suggests that even in a less than lucid state the man was somewhat aware of the damage this alien space was inducing to his mind. Navidson himself proves far more resilient to the house's influence, managing to keep a head on his shoulders throughout his multiple excursions. Yet even he, at the end of his story, when the hallways and stairways eventually give ground to a complete abyss that engulfs him, arrives at the point of giving up; his state being described as "forgetting," which the narrator equates with "dying" (Danielewski 483). One of the fictional critics cited by Zampanò makes a comparison between the house and "an immense isolation tank" where the subject "begins to create his own sensory [ ]" (330). What the individual projects (the blank space in the quote is likely meant to indicate a section of the text being illegible to Johnny), however, is consumed and negated by this space. It is impossible to leave a lasting imprint on the void, but the void itself drains those who come into contact with it of their own definition.

No character's experience of the loss of self is rendered as acute as Johnny's, though. His distress at the impersonality of the text which came into his material possession is evident, prompting him to try to ascertain as 
much information about its author as he can, in part so that he can later insert it into the text by way of his comments, alongside his own biographical narrative, which could be viewed as an effort of "enshrining" an authorial consciousness into the writing post factum. Johnny lashes out at the abyss he perceives in place of the author's presence in the text, restlessly puzzles over the paradoxes and contradictions emerging in part from the fact that a text with such an intense focus on the visual was apparently written by a blind man. The most fundamental lines of his inquiry remain unresolved, however. Confronting the tidbits gathered about Zampanò the man with the output of Zampanò the writer spurs only further incredulous questions and futile speculations. Some of these questions start to concern Johnny himself. As the task of compiling and editing the text usurps an increasing portion of his daily life, doubt is cast on his very ontological status, with Johnny confessing that on one occasion an accident where black ink got spilled on his hands made him experience a vision where "for a blinding instant I have watched my hands vanish, in fact all of me has vanished"(72); a vision accompanied by another apparent delusion in which he was stalked and attacked by "a beast" from the text's pages (the explorers express suspicion that an nonspecific beast is roaming the hallways, though no conclusive evidence of that comes to light. Hayles interprets the beast's function as that of "a signifier of absence and negation," (paraphrased in Scarano and Krause 4)). This encounter with the void likely provokes his later digression, where he articulates a notion that the text is "inventing me, defining me, directing me until finally every association I can claim as my own . . . is relegated to nothing" (Danielewski 326). In his choice to become a part of the work, Johnny undergoes self-alienation, the receding of the $I$, just as all objects recede while within the space of literature. In Blanchotian terms, he perceives "[himself] become no one, [his] interlocutor turned alien" (27). Entering the site of the work he unwillingly cedes the grasp upon his selfhood.

The cost of one's identity is not the only price levied upon those who enter the house. Another is that of facing the prospect of irremediable dissatisfaction and lack of any gratification for their efforts, or even, to take it further, a realization of one's essential impotence. Just as a literary work, while setting out unique tasks for every writer, never offers a sense of completing or achieving something of value, so does the house refuse to offer any of its visitors a passage marked by a definitive end or containing anything that could be interpreted as a reward for one's persistence, despite shifting the pattern of its interiors in response to each of them (Danielewski 165) - Zampanò's narration states that "many inter-communicating passageways encountered by individual members, even with only a glance, will never be re-encountered by anyone else again" (118), which is consistent 
with how the experience of literature is singularly unique and transient for each author or reader. In Blanchot's interpretation, the act of writing is a mediation of "what cannot cease speaking," called by the philosopher also "giant murmuring" (26), and what hence must be silenced and simultaneously made manifest by that mediation. Similarly, the explorers of the house venture into a space of infinite dimensions and boundless permutations - accompanied, one should note by an audible roar - which apparently can only cease with their departure, since, as is hypothesized in the text, the house's changes are in some way responsive to the visitor's mental state. As a result, they must elect to stop their exploration, inevitably incomplete, leave all signs of their presence to be erased by some unknown force within the house (Danielewski 162), in order to relay "their" account to the outside world.

The account will necessarily be one of a failure to capture the essence, the truth of that space, in any way that could be shared. The video and photographic recordings used by Navidson and his crew fail most patently at this, being said to "ineffectually confront the impenetrable wall of nothingness" (155) concealing the house's scale and dimensions. The mediated text of The Navidson Record fares better in that regard, thanks both to the power of language to convey that which footage gripped in darkness and without points of reference is unable to, and to the experiments with the text's composition, meant to highlight and render more tangible the concepts describing the space and its traversal - such as the void, an endless fall, or a laborious ascent. Literature turns out to be capable of conveying more about a reality in the state of withdrawal and absence - one should also note that another means of doing so utilized by Zampanò is an almost interminable list of things which were not found in the house, included in a footnote carving its way across multiple pages, as if to make the absence even more physical - It is, after all, a state that mirrors its own nature, and its property of placing the writer at a distance from what he strives to render, as opposed to the 'immediate' medium of ortographic recording, also definitely factors into it.

At this point it would be pertinent to mention that, despite being a man of images, Navidson apparently comes into contact with the written account of the house's space as well. In what ranks among the most enigmatic and arguably symbolic scenes in the novel, the photographer, after arriving at a dead end in his final exploration, brings out a book never before mentioned to be in his possession, entitled House of Leaves, and starts reading it, using the light emanating from the very book's burning pages as a source of illumination, eventually having it fully devoured by flames immediately after finishing the read. There are certainly manifold ways to view this episode, but applying the theory selected for this essay, one may conclude that it 
represents the literary space of the house finally and decisively repelling Navidson from within itself (as afterwards the man starts falling down a bottomless abyss only to emerge, with the help of his girlfriend, back in his familiar worldly surroundings). The text, the book both produced by and containing this space, manifests to him, but only in the act of its own effacement, irreversible destruction. Navidson experiences the space in its true form, but in doing so he is separated from it, witnesses it fall silent and mute, instead of capturing and preserving it, as he set out to do with his ineffectual recordings. His efforts are hence frustrated and diminished just as he fleetingly becomes intimate with what he cannot hope to remediate.

That is, however, not to say that the novel's "writerly" voice does not have to cope with the sense of frustration and powerlessness as well. It has already been mentioned how Johnny fails to ascertain any conclusive answers to his most burning questions. His engagement with Zampanò's legacy finally expires after he encounters the text he has been working on, including his editorial input, in the hands of randomly met strangers. It is left ambiguous whether this should be read as a consequence of his - unmentioned - previous actions, or as another indication of Johnny's suspect ontological status. In any case, the situation prompts him to bring his work, by his own admission incomplete and one which he does not "entirely understand" (514), to an end, as if he was sensing the text withdrawing, pushing him away. This resolution - later actualised by burning the manuscript, in accordance with the writer's inability to maintain relation with the work - causes a semblance of inner solace to return to his psyche, the underlying fear and tension giving way to a lull. However, at this point, Johnny is aware of "a Voice, which though invisible to the eye and frequently unheard by even the ear still continues, day and night, year after year, to sweep through us all" (518). The voice is likely that of literature, inspiring the always returning urge to take up writing again, to try to finish the interminable. Nonetheless, Johnny's feeling of being released from the text leads him to come to an important and apparently final conclusion regarding his past. Still, the conclusion's resounding conflict with the established facts makes one wonder where that newfound conviction originated from, whether it was not the result of Johnny realizing the absence of what he used to believe defined him, and using that realization to craft fictions which would render his existence more bearable. The memory of his mother attempting to kill him as a child is in the course of Johnny's story first brought out of the limbo of repression and then erased by the abyss, leaving room for a new narrative.

In this way, Johnny's denouement appears far more optimistic than that of Zampanò. The latter, perhaps in some part due to his blindness, heard the "Voice" so insistently that silence could come only by means of his death 
- self-inflicted in some capacity, judging from a letter he left immediately prior to it. A passage from Blanchot on the subject of fascination appears pertinent in this context:

[f]ascination is solitude's gaze. It is the gaze of the incessant and interminable. In it blindness is vision still, vision which is no longer the possibility of seeing, but the impossibility of not seeing, the impossibility which becomes visible and perseveres - always and always - in a vision that never comes to an end. (31)

In these words may lie an answer to one of Johnny's queries: the meticulously detailed account left behind by the author would then be indicative of a vision far more pervasive and overwhelming than any physical sight - a vision sprouting from fascination with literature, before which manifested literature's space of solitude, of an endless, all-consuming darkness of absence and self-negation.

Zampanò could not sate the vision with any amount of written output - when interrogated by Johnny, one woman who used to visit Zampanò "remarked that 'whatever it was he could never quite address in himself prevented him from ever settling" (xxii) - nor could he finish it in a satisfactory manner, as evidenced both by the abruptness and tonal inadequacy of the existing ending, and the pieces contained in the appendices indicating a different and far more grim direction for the story being planned (ii). Planned, though not realized, as Zampanò chose death over further preoccupation with the text, with no prospect of an end in sight. And as Blanchot asserts, the writer, "in order to sustain [the incessant Voice], has necessarily made it stop - has, in this intermittence, rendered it perceptible" (36). It is a disquieting paradox that the artist must terminate that which resounds interminably in his head and which defines him to such a great extent, must assume a stance of passivity even while an inner compulsion urges him to continue the work, and by doing so sever his connection with the text which materializes only as already withdrawing and forbidding him entry. The irresolvable nature of this quandary and the alienation deriving from it may be why the figure of a writer is so often a tragic one; it may also be treated as an argument in favour of Hayles' idea of a communication circuit as an alternative to the writer's solitude. Nonetheless, the idea does not find expression in the novel, Johnny's awareness of others picking up where he left off may factor in his subsequent relative tranquillity, but it does not prefigure any reciprocal engagement with those people - whose presence manifests in the book as notes from the conspicuously anonymous "editors." Each authorial figure in House of Leaves acts and speaks in isolation. 
Isolation, in turn, puts one in the presence of death, and indeed, according to Blanchot "[t]he work requires death, the source, to be in the work; it demands that in it the ending, which initiates all beginnings, swell up as the essence of all swelling, all unfurling and flowering" (6). Death and the consciousness of it pervade the text, the house is compared to an ancient tomb, though perhaps, as a place of loss of definition and of absence [absence to be distinguished from simple nothingness, as pointed out by Chandler Bullock, who defines the house's absence as "an ever present perpetuation of Being" (5)], it should rather be compared to "the place where someone dies." Zampanò's death initiates the plot, allows the resurgence and promulgation of his work, but there are other deaths inscribed in the text. Some of them explicitly, like those of Johnny's mother, Pelafina, and Delilah - a girl photographed by Navidson while at the edge of death - which are shown to be constitutive in turn of those characters and their narratives. Yet there seems to be another death of unspecified identity residing beneath the surface of The Navidson Record, with the scrupulously erased - and even more scrupulously retrieved by Johnny - references to the mythical Minotaur meant to hint at its presence; the presence of a consciousness swallowed by and enmeshed in the labyrinth of the text. According to some theories, the Minotaur in question stands for Pelafina, who was sentenced to exile inside the confines of an asylum. Others, however, point to Johnny himself, whose voice in the text would then be a creation of one of the other voices. The implications of the latter possibility are quite beyond the scope of this essay, though.

Just as Navidson, in his attempts to study the house, to penetrate its abyssal darkness in search of substance so as to repel the recurring memories of Delilah, tries to counteract the presence of death, so does Johnny, by working to impose order and function upon Zampanò's manuscript, struggle to nullify the death that pervades it and that its tangled, cryptic form represents. Katharine Cox writes that " $[t]$ he loss of his mother is the unfathomable abyss that infiltrates the labyrinth" (8). This essay's line of interpretation would rather state that it is the encounter with the abyss that conjures the loss. The space of the house is a space where death's presence is acute and inescapable, immanent to its interior. By compiling and editing the book Johnny could be aiming at bringing it to "life" and simultaneously pacifying it (Waltman maintains instead that Johnny intends rather to "bind the book together and bury it, take away its power, kill the monster inside it" (10), though the fact he only "buries" or destroys it after seeing its copy circulating among others seems to go against such interpretation), but in doing so he is trying to force it into a form that is not appropriate for it. Rather, it is this initial jumbled pile of pages that more accurately represented 
the nature of the work - chaotic, manic, unfinished and unconstrained, which "expresses nothing except the word being" (Blanchot 21).

Thus, one comes to surmise that the warning placed at the beginning of the novel - "[t]his is not for you" (Danielewski xix), may be a piece of advice worth heeding. For to enter the space of the house, the space of the texts comprising Danielewski's novel, is to become submerged in a dimension where immediacy is rendered unattainable, where objects and images fall to be dissolved and withdrawn, leaving a landscape of sterility, darkness, and endless void, where no meaning can be ascertained and no resolution reached. To be ensconced in a site whose provenance is in death, and where one loses one's relation to the self and others, is to come into solitude and be hounded by the underlying murmur of speech which relays only its own being, and yet also be called upon to sever one's ties to the unalterably unfinished and unsatisfactory work, and to be subsequently isolated from it for ever. Still, despite all that, the mystery and the elusive potentialities of this space serve to continuously attract the minds sensitive - and susceptible - to its reality. House of Leaves presents the readers with multiple individuals seduced by this allure, fatally in one case and near fatally in others. By its creative and eclectic use of extremely varied and daring stylistic devices, it offers genuine insight into the actual nature of that space, unrepresentable by direct means. It confronts the readers with and puts them in the position of the minds engaged in the search of literary art. It does so by distancing them from the text, by rendering the text ambiguous and suspect, by providing a near incalculable number of threads to explore, none of which can appease the readers' lust for revelations, finally by fashioning a narrative invoking an ontological anxiety, inspiring a sense of unease regarding the immutability of the laws governing the material world. The anguish of the characters lost inside the dark and inhospitable hallways of the house, witnessing the disruption of their identities and the undermining of their agencies, engenders itself, to a certain extent, to the readers as well, so that all partake of the solitude of one - even momentarily - no longer at home with mankind.

\section{Works Cited}

Blanchot, Maurice. The Space of Literature. Trans. Ann Smock. University of Nebraska Press, 1989. 
Bullock, Chandler. "Undoing the Void: the Desire for Absence in Danielewski's House of Leaves."Academia.edu, 22 June 2015. www.academia.edu/14363865/UNDOING_THE_VOID_THE_DESIRE_ FOR_ABSENCE_IN_DANIELEWSKI_S_HOUSE_OF_LEAVES. Accessed 21 Aug. 2017.

Cox, Katharine. "What Has Made Me? Locating Mother in the Textual Labyrinth of Mark Z. Danielewski's House of Leaves." Critical Survey, edited by Graham Holderness and Bryan Loughrey, vol. 18, no. 2, 2006, pp. 4-15.

Danielewski, Mark Z. House of Leaves. The Remastered Full Color Edition. Pantheon, 2000.

Hayles, N. Katherine. "Saving the Subject: Remediation in House of Leaves." American Literature, edited by Priscilla Wald. 74.4, 2002, pp. 779-806.

Scarano, Matthew Scott, and Jennifer Ann Krause. "Reality and Existentialism in House of Leaves." Vanderbilt Undergraduate Research Journal, edited by Jessica Miles, vol. 7, 2011. ejournals.library.vanderbilt. edu/index.php/vurj/article/view/2918. Accessed 20 Aug. 2017.

Waltman, Melanie. "Voices from the Darkness: A House of Leaves Experience." Honors Projects, 10, 2009. http://digitalcommons.iwu.edu/ theatre honproj/10. Accessed 21 Aug. 2017. 